\title{
Plains End Power Station - gas reciprocating engines in a grid-stability power plant
}

\begin{abstract}
The Plains End Power Station located in Colorado, USA, is one of the largest power plants with reciprocating engines as prime movers. In two units of this power plant there are totally 34 engine-generator sets driven by Wartsila reciprocating engines. Total installed capacity of the plant is ca. 230 MW. Plains End Power Station serves a source of peakload power and grid-stability plant, which is particularly important in an area with high wind power capacity. Features of the used engines like their high operational flexibility and very short start-up time, combined with the layout of multiple parallel gensets of relatively small outputs, greatly facilitates this type of operations, allowing to quickly and reliably supply amount of power currently needed for grid balancing. The paper presents operational experience and specific operational conditions of a peakload and grid-stability plant using gas reciprocating engines.
\end{abstract}

Key words: grid-stability plant, power industry, gas enegines

\section{Elektrownia Plains End - gazowe silniki tlokowe jako moc interwencyjna w systemie elektroenergetycznym}

\begin{abstract}
Zlokalizowana w stanie Kolorado Elektrownia Plains End jest jednym z większych świecie obiektów energetycznych wykorzystujących silniki tłokowe jako podstawowe urządzenia wytwórcze. W dwóch blokach tej elektrowni pracują łacznie 34 zespoły prądotwórcze z gazowymi silnikami tłokowymi Wärtsilä. Łączna moc zainstalowana obiektu wynosi ok. 230 MW. Elektrownia Plains End stuży jako źródło mocy szczytowej i interwencyjnej, szczególnie cenne w rejonie o wysokim poziomie mocy zainstalowanej $w$ turbinach wiatrowych. Cechy zastosowanych silników, takie jak wysoka elastyczność oraz bardzo krótki czas rozruchu, jak również zastosowany układ z wieloma równoległymi jednostkami o względnie niewielkich mocach znaczaco sprzyjają takiemu trybowi eksploatacji pozwalając na szybkie i niezawodne dostarczenie mocy aktualnie potrzebnej do zbilansowania sieci. W referacie przedstawione zostały doświadczenia eksploatacyjne oraz specyficzne warunki eksploatacji obiektu szczytowego i interwencyjnego opartego o gazowe silniki tłokowe.
\end{abstract}

Słowa kluczowe: moce interwencyjne, energetyka, silniki gazowe

\section{Grid-stability power}

Reliable operation of the power grid requires constant availability of a certain reserve power output which can quickly come into operation in case of any distortions in the grid. Traditionally each system had to deal with a possibility of a trip of any connected power unit or break down of a transmission line. Reserve capacity therefore had to be adapted to the grid topography and outputs of individual power units in a given area. The reserve capacity is intended to assure balancing power within the system in case of distortions and to allow keeping constant parameters in the grid (voltage, frequency).

Traditional methods for assuring back-up power in the grid are:

- Hydro power plants, particularly pumped storage plants

- Gas turbine power stations

- Spinning reserve.

The most effective method is to utilize hydro power. It can achieve its nominal output in approximately one minute from start-up command. Unfortunately construction of hydro plants is limited by geography.

Spinning reserve seems to be the easiest method of assuring reserve power. It requires operating some of the power units at partial loads. In case of emergency extra power is delivered simply by increasing output of those units. Spin-

\section{Moc interwencyjna}

Niezawodna praca systemu elektroenergetycznego wymaga, by w każdej chwili dostępna była określona moc rezerwowa, która może szybko wejść do pracy na wypadek wystąpienia zakłóceń $\mathrm{w}$ pracy systemu. Tradycyjnie w każdym systemie należało liczyć się na przykład z nieplanowanym wyjściem z pracy dowolnego bloku energetycznego lub przerwą w pracy linii przesyłowej. Rozmiary rezerwy dostosowywane były do topografii sieci przesyłowej oraz rozmiaru jednostek wytwórczych na danym obszarze. Rolą mocy interwencyjnej jest zapewnienie zbilansowania mocy w systemie na wypadek wystąpienia zakłóceń oraz utrzymanie stałych parametrów w sieci (napięcie, częstotliwość).

Tradycyjnymi metodami zapewniania mocy interwencyjnych w systemie elektroenergetycznym są:

- elektrownie wodne, szczególnie szczytowo-pompowe,

- elektrownie z turbinami gazowymi,

- utrzymywanie rezerwy wirującej.

Najefektywniejszym rozwiązaniem jest wykorzystywanie elektrowni wodnych. Są one zdolne do osiągnięcia pełnej mocy zainstalowanej w ciągu około jednej minuty od rozpoczęcia rozruchu. Niestety budowa elektrowni wodnych jest ograniczona przez uwarunkowania geograficzne.

Rezerwa wirująca jest $\mathrm{z}$ kolei najprostszym sposobem zapewnienia rezerwy mocy. Metoda ta polega na utrzymy- 
ning reserve can be maintained by practically every thermal power plant and hydro plants as well. It assures very fast reaction times. This method however has two major drawbacks: control range is limited by the minimal output of a given power generation unit, and part-load operations result with lower power generation efficiency. This solution is therefore energetically ineffective.

When it is not possible (or not feasible) to provide all needed reserve output in hydro power plants and/or as spinning reserve, it becomes necessary to construct specialized power generation units able to start-up and ramp-up very fast. Of course not all power generation technologies give such a possibility. Useful concepts, except for hydro plants, include various solutions based on liquid and gaseous fuels. Traditionally grid-stability services are provided by gasturbine power stations. Aeroderivative GTs can ramp-up to their nominal power output from a cold start conditions in approximately 15 minutes, and in case of the newest models the time gets closer to 10 minutes. Recently however also reciprocating engines enjoy significant popularity in a gridstability role, among them spark-ignited gas engines.

Over last two decades requirements for grid stability power capacity in developed countries increased considerably. Three reasons for this can be named:

- Increased capacity of individual baseload power units

- Increased requirements concerning electricity quality

- Rapid development of weather-dependent renewable power.

Because of the first of those factors there must be a possibility to replace the largest power unit connected to the grid, which can suddenly trip from any reason (today this might be a $1600 \mathrm{MWel}$ nuclear unit).

The second factor requires more exact balancing to avoid intolerable distortions.

The most important however is the third factor, related to popular use of renewable energy sources, particularly wind power. Rapid development of this technology can significantly distort grid operations. Large concentration of wind turbines on a limited area can result with sudden losses of considerable power supply in case of decrease or increase (over design maximum) of the wind speed. Fast growth of wind power installed capacity can prove particular challenge for the Polish grid, where the generation is based on inflexible coal-fired power stations and additionally the grid itself is underdeveloped.

Necessity to provide appropriate balancing power for a power grid with significant capacity installed in wind turbines is well visible on the charts presented below. Fig. 1 shows forecasts of wind power supply to the E.ON-Netz grid in Germany for February 2008 (24-hour forecasting). Fig. 2 shows actual power output of wind turbines in that month. Fig. 3 presents difference between forecasts and real life generation.

Fig. 3 shows that maximum shortage of power due to erroneous forecasts reached $2000 \mathrm{MW}$, with a peak power output of wind turbines slightly below 8000 MW. Study [4] suggests that it is desirable to install reserve capacity equal waniu w ruchu bloków energetycznych pracujących z obciążeniem częściowym. Dostarczenie mocy rezerwowej do systemu sprowadza się do zwiększenia mocy wyznaczonych jednostek wytwórczych. Rezerwę wirującą można utrzymywać praktycznie we wszystkich elektrowniach systemowych cieplnych i wodnych. Umożliwia też ona szybkie dostarczenie mocy interwencyjnej do systemu. Metoda ta ma jednak dwie zasadnicze wady: zakres regulacji ograniczony jest minimum technicznym mocy danej jednostki wytwórczej, a sama praca na obciążeniach częściowych powoduje spadek sprawności wytwarzania energii elektrycznej. Jest to zatem rozwiązanie nieefektywne energetycznie.

W razie braku możliwości (bądź nieopłacalności) zapewnienia odpowiedniej rezerwy mocy w elektrowniach wodnych i/lub w postaci rezerwy wirującej, konieczne jest zapewnienie specjalizowanych obiektów energetycznych, zdolnych do szybkiego wejścia do pracy. Rzecz jasna nie wszystkie technologie energetyczne zapewniają taką możliwość. Poza elektrowniami wodnymi użyteczne są tutaj obiekty na paliwa płynne - ciekłe i gazowe. Tradycyjnie w roli mocy interwencyjnych stosowane są turbiny gazowe. Lotniczopochodne modele turbin gazowych charakteryzują się czasem osiągnięcia mocy znamionowej ze startu zimnego rzędu 15 minut, a w przypadku najnowszych modeli czas ten zbliża się do 10 minut. W ostatnich latach obserwowane jest jednak także wykorzystanie w tej roli nowoczesnych silników tłokowych o zapłonie iskrowym.

W ciągu ostatnich dwóch dekad znacznie zwiększyły się wymagania dotyczące mocy interwencyjnych w systemach elektroenergetycznych państw rozwiniętych. Można wyróżnić trzy przyczyny takiego stanu rzeczy:

- wzrost mocy zainstalowanej pojedynczych bloków energetycznych elektrowni podstawowych,

- wzrost wymagań dotyczących jakości energii elektrycznej,

- gwałtowny rozwój zależnej od pogody energetyki odnawialnej.

Pierwszy z tych czynników sprawia, że większa moc rezerwowa musi być dostępna dla zbilansowania systemu $\mathrm{w}$ razie nieplanowanego wyjścia z pracy wielkiego bloku energetycznego (przykładowo bloku jądrowego o mocy $1600 \mathrm{MW}_{\mathrm{e}}$ ).

Drugi element narzuca konieczność coraz dokładniejszego bilansowania systemu dla uniknięcia zakłóceń w pracy sieci.

Najistotniejszy jednak jest trzeci element, związany z wykorzystaniem energetyki odnawialnej, szczególnie turbin wiatrowych. Szerokie wykorzystanie tej technologii prowadzić może do zakłóceń w pracy systemu energetycznego. Duża koncentracja turbin wiatrowych na ograniczonym obszarze może prowadzić do nagłego spadku mocy dostarczanej do systemu w razie nagłego spadku lub wzrostu (ponad maksimum konstrukcyjne turbiny) prędkości wiatru. Gwałtowny rozwój energetyki wiatrowej może okazać się szczególnym wyzwaniem dla polskiego systemu elektroenergetycznego, w którym wytwarzanie oparte jest na nieelastycznych elektrowniach węglowych, a dodatkowo sieć przesyłowa jest słabo rozwinięta i niedoinwestowana. 


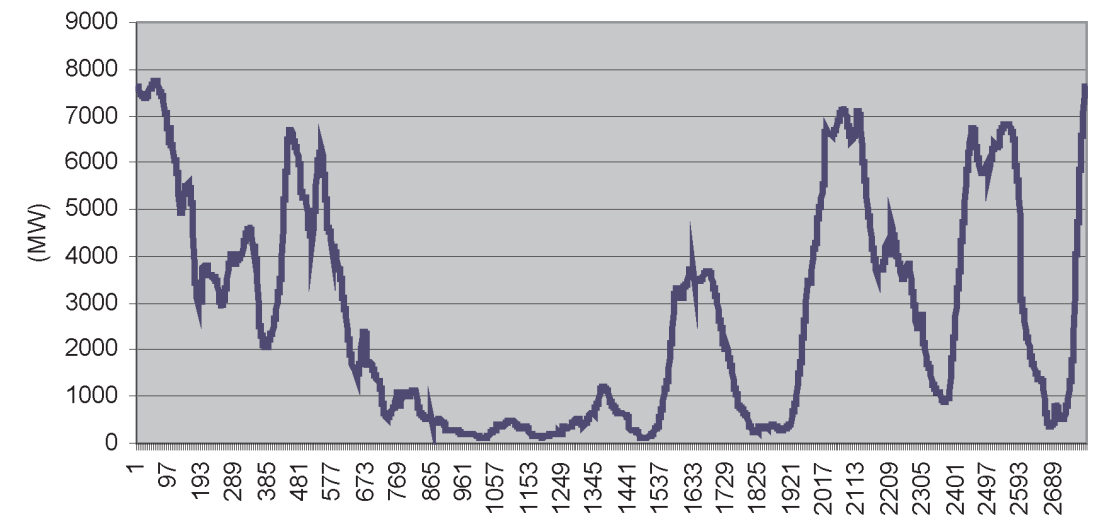

Fig. 1. Forecast of power generated by wind turbines in February 2008, E.ON-Netz, Germany Rys. 1. Prognoza mocy z elektrowni wiatrowych, luty 2008 r., E.ON-Netz, Niemcy

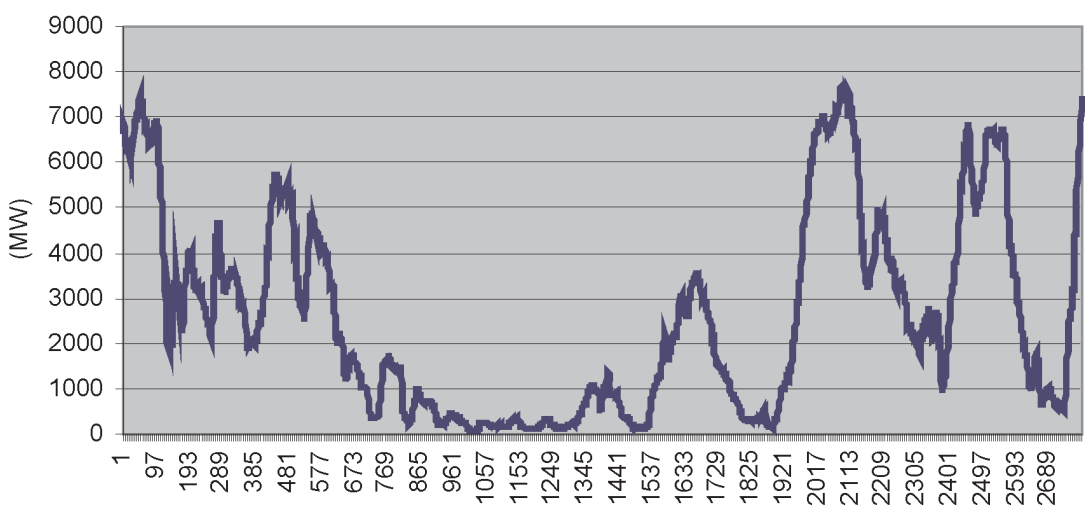

Fig. 2. Power actually generated by wind turbines in February 2008, E.ON-Netz, Germany Rys. 2. Rzeczywista moc elektrowni wiatrowych w lutym 2008 r., E.ON-Netz, Niemcy
Konieczność zapewnienia odpowiedniego bilansowania systemu elektroenergetycznego z dużą mocą zainstalowaną $\mathrm{w}$ turbinach wiatrowych dobrze obrazują przedstawione poniżej wykresy. Rys. 1 przedstawia prognozę mocy dostarczanej do sieci E.ON-Netz w Niemczech w lutym 2008 (prognozowanie 24-godzinne). Rys. 2 ukazuje rzeczywistą moc wyprodukowaną przez turbozespoły wiatrowe. Na rys. 3 zaprezentowano różnice pomiędzy prognozami a rzeczywistą produkcją.

$\mathrm{Z}$ rys. 3 wynika, że maksymalny niedobór mocy w wyniku błędnych prognoz sięgnął 2000 MW przy maksymalnej mocy dostarczanej $\mathrm{z}$ turbin wiatrowych do systemu na poziomie nieco poniżej 8000 MW. Opracowanie [4] sugeruje zapewnianie rezerwy zdolnej do szybkiego uruchomienia na poziomie $28 \%$ mocy zainstalowanej w farmach wiatrowych w danym rejonie. Według informacji udostępnionych przez prezes PSE Operator Stefanię Kasprzyk budowa farm wiatrowych o łącznej mocy 8000 MW w Polsce oznaczać będzie konieczność budowy elektrowni rezerwowych o łącznej mocy $1900 \mathrm{MW}(23,75 \%)$ [1]. to $28 \%$ of wind capacity installed in a given area. According to the information published by the President of PSE Operator (Polish transmission grid operator) Mrs Stefania Kasprzyk construction of wind turbines with total capacity of $8000 \mathrm{MWel}$ in Poland will require to install $1900 \mathrm{MWel}$ of backup power $(23.75 \%)$ [1].

\section{Gas-fired reciprocating engine as a grid stability} power generation unit

Reciprocating engines are quite popularly used as sources of backup power for industrial plants, commercial facilities, office buildings etc. Typical example of using high-power engines in a role of backup power are nuclear power plants. In those cases however mostly Diesel engines running on liquid fuels are used. They can achieve full power output below 60 seconds from the start-up command. Spark-ignited engines fuelled with gas are a bit slower to ramp-up, nevertheless their performance is totally sufficient for assuring grid-stability services. With appropriately configured start-up

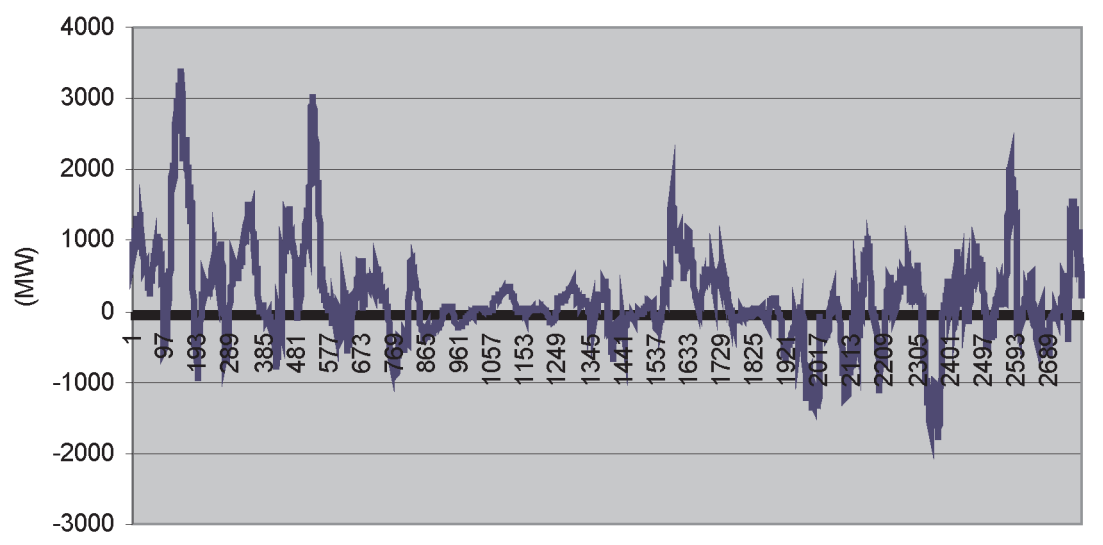

Fig. 3. Forecasting error (forecast minus actual power) for wind turbines, February 2008, E.ON-Netz, Germany

Rys. 3. Błąd prognozy mocy (prognoza pomniejszona o moc rzeczywista) dostarczanej przez elektrownie wiatrowe w lutym 2008 r., E.ON-Netz, Niemcy

\section{Gazowy silnik tlokowy w roli źródła mocy rezerwowej}

Silniki tłokowe są od dawna stosowane jako źródła mocy rezerwowej dla obiektów przemysłowych, handlowych, biurowych i innych. Typowym przykładem użycia dużej mocy silników jako źródła mocy rezerwowej są elektrownie jądrowe. W takich przypadkach stosowane są jednak silniki 
system (starting air injection to all cylinders at sufficiently high pressure) it is possible to get full output well below 10 minutes. This result is considerably better than any gas turbine can achieve. High-power reciprocating engines also display better energy conversion efficiency than turbines and flatter efficiency curve which means higher efficiency at part-load operations. Engine-generator sets with output of approximately $10 \mathrm{MW}$ each can achieve gross electrical efficiency around $44 \%$ - only largest gas turbines, with outputs above $100 \mathrm{MW}$ can compete with that value. Additional advantages result from a different concept of an engine-based power station. Gas-turbine grid stability plants have usually one or two turbine units only. An engine-based plant has usually ten or more smaller units. This approach - combined with flat efficiency curve and low minimum output of an engine - allows an engine-based plant to work in a very wide range of power outputs at very high efficiency values. For instance a $100 \mathrm{MW}$ plant of $10 \times 10 \mathrm{MW}$ engines can deliver practically any output between 3 and $100 \mathrm{MW}$, and appropriate management of individual units' start-ups and shut-downs allows operation on almost-nominal efficiency in practically entire range. Additional advantage of having multiple units is increased plant availability and reliability, and possibility to carry out maintenance or major overhauls without necessity to shut down entire plant - overhaul of one engine only slightly decreases capabilities. The major drawback of this solution is necessity to provide sufficiently large area to construct a plant with multiple reciprocating engines.

\section{Plains End Power Plant}

Located in Colorado (Denver area), the Plains End Power Plant provides intermediate-load and peakload poawer, as well as ancillary (grid-stability) services - both with readyto-start engines and spinning reserve. The plant consists of two parts. Plains End I was commissioned on 1 May 2002 and has installed capacity of $113 \mathrm{MWel}$. It is equipped with 20 sets with Wärtsilä 18V34SG engines. The Plains End II extension commissioned in 2008 is further 14 power generating sets with newer Wärtsilä 20V34SG engines, with total output of $118 \mathrm{MWel}$. The engines are fuelled with grid natural gas, with a methane number between 75 and 84, and LHV of some $34 \mathrm{MJ} / \mathrm{Nm}^{3}$. Except for the newer model of engines with higher specific power, the extension incorporated some features resulting from lessons learned on the first plant. Among these were increased engine hall ventilation efficiency and installation of frequency converters on cooling radiators, allowing to cut down own consumption of the plant during partial load operations or simply colder weather.

Until now the engines of the Plains End I have an average of 8000 running hours per unit, while those of the Plains End II -5000 hours each. During last few years the first plant has been operated some 1500 hours a year, while the extension $3000 \mathrm{~h} / \mathrm{a}$. Operational schedule is planned to avoid multiple engine overhauls at the same time. This allows to keep the plant in operation during maintenance of individual units.

When providing ancillary services the engine-generator sets (all at once or individually) can achieve full power in o zapłonie samoczynnym zasilane paliwami ciekłymi, zdolne do osiągnięcia pełnej mocy w czasie poniżej 60 sekund. Silniki o zapłonie iskrowym zasilane paliwem gazowym wykazują nieco mniejszą elastyczność, która jednakże jest całkowicie wystarczająca do stosowania ich jako źródeł mocy interwencyjnej w systemie elektroenergetycznym. Przy zastosowaniu odpowiednio skonfigurowanego układu rozruchowego (pneumatyczny wtrysk powietrza sprężonego do wszystkich cylindrów) możliwe jest osiągnięcie czasu uzyskania pełnej mocy znamionowej znacznie poniżej 10 minut. Jest to wynik istotnie lepszy od osiąganego przez najbardziej zaawansowane turbiny gazowe. Silniki tłokowe wielkich mocy charakteryzują się przy tym korzystniejszą od turbin gazowych sprawnością konwersji energii oraz mniejszą utratą sprawności przy obciążeniach częściowych. Silniki gazowe o mocach rzędu kilku-kilkunastu megawatów osiągają sprawności wytwarzania energii elektrycznej brutto na poziomie $44 \%$ - porównywalne parametry wykazują jedynie najbardziej zaawansowane modele turbin gazowych o mocach przekraczających 100 MW. Dodatkowe zalety wynikają z odmiennej koncepcji budowy obiektów rezerwowych wykorzystujących silniki tłokowe. Elektrownie interwencyjne $\mathrm{z}$ turbinami gazowymi składają się na ogół z jednej lub dwóch jednostek wytwórczych. Obiekt oparty o silniki tłokowe posiada natomiast wiele (kilka-kilkanaście) mniejszych zespołów. Dzięki takiemu podejściu - jak również płaskiej charakterystyce sprawności i niskiemu minimum technicznemu pojedynczych jednostek - możliwe jest osiągnięcie przez obiekt bardzo szerokiego zakresu mocy przy wysokiej sprawności. Przykładowo dla obiektu o mocy 100 MW składającego się z 10 silników o mocy 10 MW każdy, osiągalna będzie praktycznie każda moc z zakresu $3 \div 100 \mathrm{MW}$, a odpowiednie uruchamianie i odstawianie poszczególnych zespołów prądotwórczych umożliwi pracę ze sprawnością zbliżoną do sprawności znamionowej pojedynczego zespołu w bardzo szerokim zakresie mocy. Dodatkową zaletą dużej ilości równoległych jednostek jest zwiększona niezawodność oraz możliwość prowadzenia remontów przy jednoczesnym utrzymywaniu gotowości do pracy przy nieco tylko zmniejszonej mocy. Główną wadą jest konieczność zapewnienia większej przestrzeni na budowę obiektu wyposażonego w wiele silników tłokowych.

\section{Elektrownia Plains End}

Zlokalizowana w amerykańskim stanie Kolorado (w rejonie Denver) elektrownia Plains End zapewnia dostawy energii podszczytowej, szczytowej, a także usługi mocy interwencyjnej i rezerwę wirującą. Obiekt składa się z dwóch części. Elektrownia Plains End I uruchomiona 1 maja 2002 dysponuje mocą zainstalowaną $113 \mathrm{MW}_{\mathrm{e}}$ i posiada 20 zespołów prądotwórczych z silnikami tłokowymi typu Wärtsilä 18V34SG. Przekazane do eksploatacji w 2008 r. rozszerzenie Plains End II to kolejnych 14 zespołów z nowszymi silnikami Wärtsilä 20V34SG o łącznej mocy 118 MW. Silniki zasilane są sieciowym gazem ziemnym o liczbie metanowej $\mathrm{w}$ zakresie $75 \div 84$ i wartości opałowej rzędu $34 \mathrm{MJ} / \mathrm{Nm}^{3}$. Poza nowszym modelem silników o większej mocy jednostkowej projekt drugiej części elektrowni uwzględnia doświadczenia 
7 minutes 45 seconds when starting up from preheated conditions. In practice the transmission system operator only requires the time to be below 10 minutes. The generator synchronizes with the grid in time below 2 minutes. Then the load can be increased at a rate of maximally $20 \%$ of nominal power per minute. Preheated condition is maintained with electrical heaters with a total power of $2 \times 30 \mathrm{~kW}$ per engine, though in most cases only one is in use. Engines are started up with injection of compressed air into cylinders. Fig. 4 presents a start-up curve registered by automation system on one of the engine-generator sets of the Plains End I.

Waste heat from the engines is dumped to the ambient air through radiators. Therefore there are no losses of water from the cooling system during normal operation and no water demand from the plant.

Plains End Power Plant is remotely dispatched by the distribution system operator. During first five years of operation the Plains End I was operated by the personnel of the supplier, Wärtsilä company. After the extension had been finished though the operation and maintenance was taken over by the Cogentrix company. Currently the crew of the power plant is 13 persons, including the plant manager, operational manager, one person of office staff and 10 operators, who also perform minor maintenance operations.

\section{Wärtsilä 34SG engine}

Wärtsilä 34 SG engines installed at the Plains End Power Plant are turbocharged four-stroke spark-ignited reciprocating engines operating at nominal speed of $720 \mathrm{rpm}$. They are coupled to synchronous generators with four pairs of poles through flexible couplings. Each engine-generator set is installed on a common base frame, which in turn is settled over the foundation with flexible vibration dampers. Table 1 shows technical data of a single power generation set based on a Wärtsilä 20V34SG engine in $50 \mathrm{~Hz}$ and $60 \mathrm{~Hz}$ options.

Cylinders of Wärtsilä 34SG engines are fitted with prechambers. Fuel is injected to the pre-chamber (through a mechanically-controlled valve) and through electronically-

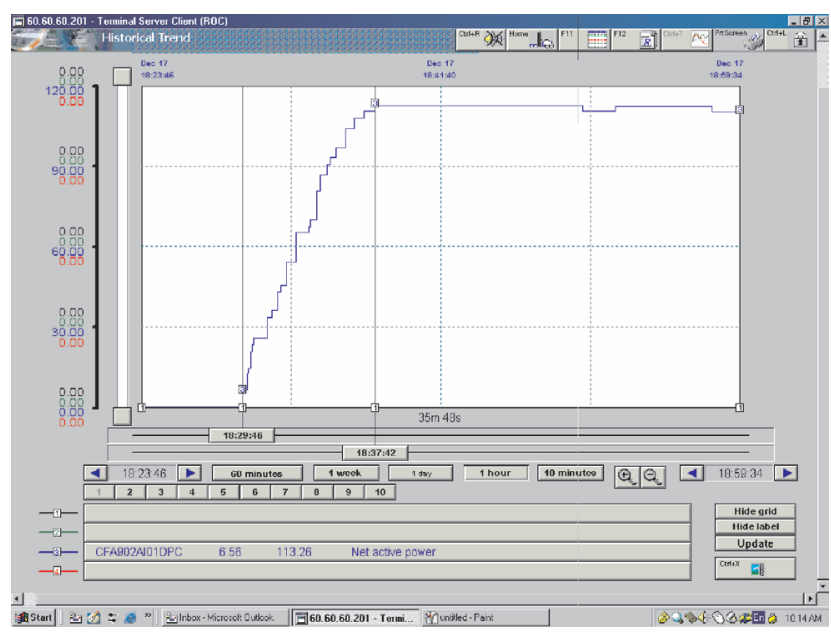

Fig. 4. Record of a start-up procedure at one of the units at Plains End I. Note the increase from 0 to $100 \%$ load in 7 minutes 56 seconds [2]

Rys. 4. Zapis rozruchu zespołu prądotwórczego z Elektrowni Plains End I. Widoczny przyrost mocy od 0 do $100 \%$ w ciagu 7 minut 56 sekund [2] eksploatacyjne pierwszego bloku. Zwiększona została wydajność wentylacji hali maszynowni. Silniki elektryczne napędzające wentylatory chłodni suchych zostały zaopatrzone w przemienniki częstotliwości. Pozwala to na zmniejszenie zużycia energii na potrzeby własne przy pracy z obciążeniami częściowymi lub przy niższej temperaturze otoczenia, gdy wymaganą intensywność chłodzenia zapewnia mniejszy przepływ powietrza.

Do chwili obecnej zespoły zainstalowane w Plains End I przepracowały średnio po 8000 godzin, natomiast nowsze jednostki w Plains End II - po 5000 godzin. Plains End I w ostatnich latach pracuje przez ok. 1500 godzin rocznie, natomiast nowsza część elektrowni - po 3000 godzin na rok. Plan eksploatacji elektrowni zakłada przy tym nierównomierny przyrost czasu pracy silników tak, by planowe remonty nie wypadały w tym samym czasie. Pozwala to na utrzymywanie obiektu $\mathrm{w}$ ruchu podczas prowadzenia przeglądów poszczególnych jednostek.

W przypadku świadczenia usług interwencyjnych, zespoły prądotwórcze (wszystkie lub pojedynczo) są w stanie osiągnąć pełną moc w ciągu 7 minut 45 sekund przy starcie ze stanu podgrzanego; w praktyce operator systemu przesyłowego wymaga czasu w granicach 10 minut. Synchronizacja $\mathrm{z}$ siecią następuje w czasie poniżej 2 minut. Obciążenie silników można zmieniać o maksymalnie $20 \%$ w ciągu minuty. Stan podgrzany utrzymywany jest za pomocą podgrzewaczy elektrycznych o mocy łącznej $2 \times 30$ kW na zespół prądotwórczy (w większości przypadków wykorzystywany jest tylko jeden). Rozruch silników odbywa poprzez wtrysk sprężonego powietrza do cylindrów. Rys. 4 przedstawia krzywą rozruchu zarejestrowaną przez układ automatyki na jednym z zespołów prądotwórczych Plains End I.

Odprowadzanie ciepła z układu chłodzenia silników realizowane jest za pośrednictwem suchych chłodni wentylatorowych. Nie ma zatem strat wody chłodzącej w czasie normalnej eksploatacji obiektu.

Elektrownia Plains End sterowana jest zdalnie przez operatora systemu przesyłowego. W ciągu pierwszych pięciu lat istnienia Plains End I bieżąca eksploatacja prowadzona była przez personel dostawcy technologii, firmy Wärtsilä. W tym czasie stały personel obiektu składał się z 5 osób, pracujących przez 20 lub 24 godziny na dobę. Po rozszerzeniu eksploatację bieżącą elektrowni przejęła firma Cogentrix. Aktualna załoga składa się z 13 osób, w tym kierownika obiektu, kierownika eksploatacji, jednej osoby do obsługi biurowej oraz 10 operatorów, którzy wykonują także bieżące przeglądy.

\section{Silnik Wärtsilä 34SG}

Silniki serii Wärtsilä 34SG zastosowane w blokach Elektrowni Plains End to turbodoładowane czterosuwowe silniki o zapłonie iskrowym, pracujące z prędkością znamionową 720 $\mathrm{obr} / \mathrm{min}$. Są one sprzęgnięte $\mathrm{z}$ generatorami synchronicznymi o czterech parach biegunów za pośrednictwem sprzęgieł podatnych. Każdy zespół silnik-generator zainstalowany jest na wspólnej ramie nośnej, która osadzona jest na fundamencie za pośrednictwem sprężystych elementów tłumiących drgania. Tabela 1 przedstawia dane pojedynczego zespołu prądotwór- 
controlled main gas admission valves located immediately upstream of the of cylinder inlet valves, individually for each cylinder. Air/fuel ratio in the pre-chamber is ca. 1, while in the main chamber it is approximately 2.1 (lean-burn concept). Independent control of gas admission valve for each cylinder assures optimization of combustion process and maximization of engine's efficiency.

Table 1. Technical parameters of an engine-generator set with Wärtsilä 20V34SG prime mover [5]

Tabela 1. Dane techniczne zespolu prądotwórczego z silnikiem Wärtsilä 20V34SG [5]

\begin{tabular}{|l|c|c|c|}
\hline Parameter/parametr & $\begin{array}{c}\text { Unit/ } \\
\text { jednostka }\end{array}$ & $\begin{array}{c}50 \mathrm{~Hz} \\
\text { option/ } \\
\text { wersja } \\
50 \mathrm{~Hz}\end{array}$ & $\begin{array}{c}60 \mathrm{~Hz} \\
\text { option/ } \\
\text { wersja } \\
60 \mathrm{~Hz}\end{array}$ \\
\hline $\begin{array}{l}\text { Number of cylinders/liczba i uktad } \\
\text { cylindrów }\end{array}$ & - & $20 \mathrm{~V}$ & \\
\hline Bore/średnica cylindra & $\mathrm{mm}$ & 340 & \\
\hline Stroke/skok tłoka & $\mathrm{mm}$ & 400 & \\
\hline Compression ratio/stopień sprężania & - & \multicolumn{2}{|c|}{$12^{1)}$} \\
\hline BMEP/średnie ciśnienie efektywne & $\mathrm{bar}$ & 20.0 & 19.8 \\
\hline $\begin{array}{l}\text { Medium piston speed/średnia pręd- } \\
\text { kość tłoka }\end{array}$ & $\mathrm{m} / \mathrm{s}$ & 9.6 & 10.0 \\
\hline $\begin{array}{l}\text { Gross electric power/moc elektrycz- } \\
\text { na brutto }\end{array}$ & $\mathrm{kW}$ & 8730 & 8439 \\
\hline $\begin{array}{l}\text { Electrical efficiency/sprawność } \\
\text { elektryczna }\end{array}$ & $\%$ & 44.3 & 44.3 \\
\hline
\end{tabular}

\section{Conclusions}

The Plains End Power Plant is a successful example of gas engine application for peakload and grid-stability purposes. Positive experience from operation of the first plant resulted with further extension which doubled installed capacity. Plains End proves itself very well as a source of emergency and peakload power in the area with high capacity installed in wind turbines. Short start-up times, technical solutions of installed engines, and modularity of the whole plant assure operational flexibility needed for this type of duty, high availability, and high efficiency of power generation, both at full and part load operation. czego z silnikiem Wärtsilä 20V34SG przystosowanego do współpracy z siecią o częstotliwościach 60 oraz $50 \mathrm{~Hz}$.

Silniki Wärtsilä 34SG posiadają cylindry ze wstępną komorą spalania. Paliwo podawane jest do komory wstępnej (zawór sterowany mechanicznie) oraz do kanałów dolotowych każdego cylindra osobno (zawór sterowany elektronicznie). W komorze wstępnej współczynnik nadmiaru powietrza wynosi ok. 1, podczas gdy w głównej komorze spalania przyjmuje on wartość ok. 2,1. Niezależnie sterowane wtryskiwacze paliwa gazowego zapewniają optymalizację pracy poszczególnych cylindrów, a zatem maksymalizację sprawności całego silnika.

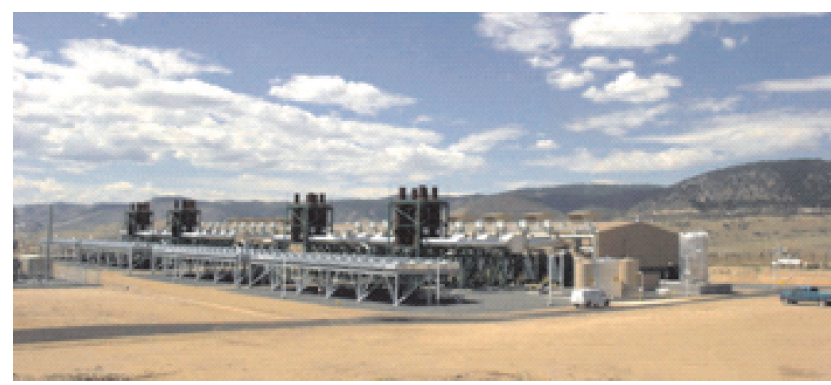

Fig. 5. Plains End power station view Rys. 5. Widok Elektrowni Plains End

\section{Wnioski}

Elektrownia Plains End jest udanym przykładem zastosowania koncepcji elektrowni szczytowej i interwencyjnej wykorzystującej technologię gazowych silników tłokowych. Pozytywne doświadczenia z eksploatacji pierwszego bloku doprowadziły do rozbudowy obiektu i podwojenia jego mocy zainstalowanej. Elektrownia Plains End sprawdza się dobrze w roli źródła mocy szczytowej i rezerwowej w rejonie, w którym zainstalowana jest wysoka moc w turbinach wiatrowych. Krótkie czasy rozruchu, rozwiązania techniczne zastosowanych silników oraz modułowość elektrowni zapewniają wymaganą w takim zastosowaniu elastyczność pracy, dyspozycyjność oraz wysoką sprawność przy pracy z obciążeniem znamionowym i przy obciążeniach częściowych.

Paper reviewed/Artykut recenzowany

\section{Bibliography/Literatura}

[1] Chojnacki I.: Obok wiatraków muszą powstać rezerwowe elektrownie za 7 mld zł, [w:] Gazeta Prawna, 17 lipca 2009.

[2] Finn D., Ancillary Service Benefits. PowerGen International 2005, Las Vegas, grudzień 2005.

[3] Heikkinen J.: The effects of growth in wind power capacity. Example from the USA. Debata „Bezpieczeństwo energetyczne Metropolii Polskich”, Warszawa, luty 2009.

\footnotetext{
1) In case of using fuel with lower methane numbers, compretion ratio of $11 \mathrm{is} \mathrm{used/w} \mathrm{przypadku} \mathrm{paliwa} \mathrm{o} \mathrm{niższej} \mathrm{liczbie} \mathrm{metanowej} \mathrm{stosowany} \mathrm{jest}$ stopień sprężania 11.

2) Tolerance $0 \%$, gas fuel methane number $\geq 80 /$ przy tolerancji $0 \%$, liczba metanowa paliwa $\geq 80$.
}

[4] Vuorinen A.: Planning of Optimal Power Systems - 2009 Edition. Ekoenergo, Vammala, 2009.

[5] Wärtsilä 34SG Engine Technology. Wärtsilä Corporation, Helsinki, 2009.

Mr. Adam Rajewski, MSc., MEng. - Assistant Lecturer at the Institute of Heat Engineering, Warsaw University of Technology, Sales Support Engineer, Wartsila Polska Sp. z o.o.

mgr inż. Adam Rajewski, asystent w Instytucie Techniki Cieplnej Politechniki Warszawskiej, inżynier wsparcia sprzedaży w firmie Wartsila Polska Sp. z o.o. e-mail: adam.rajewski@wartsila.com

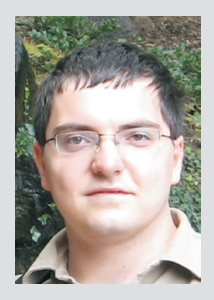

